\title{
A GENERALIZATION OF A THEOREM BY CHEO AND YIEN CONCERNING DIGITAL SUMS
}

CURTIS N. COOPER and ROBERT E. KENNEDY

Department of Mathematics and Computer Science

Central Missouri State Univeraity

Warrensburg, Missouri 64093 U.S.A.

(Received January 20, 1986)

ABSTRACT. For a non-negative integer $n$, let $s(n)$ denote the digital sum of $n$. Cheo and Yien proved that for a positive integer $x$, the sum of the terms of the sequence

$$
\{\mathrm{s}(\mathrm{n}): \mathrm{n}=0,1,2, \ldots,(\mathrm{x}-1)\}
$$

is $(4.5) x \log x+0(x)$. In this paper we let $k$ be a positive integer and determine that the sum of the sequence

$$
\{\mathrm{s}(\mathrm{kn}): \mathrm{n}=0,1,2, \ldots,(\mathrm{x}-1)\}
$$

is also $(4.5) x \log x+0(x)$. The constant implicit in the big-oh notation is dependent on $\mathrm{k}$.

KEY WORDS AND PHRASES. Digital sums.

1980 MATHEMATICS SUBJECT CLASSIFICATION CODE. $10 \mathrm{H} 25$

1. INTRODUCTION.

In Cheo and Yien [1], it was proven that for a positive integer $\mathbf{x}$,

$$
\mathrm{n} \stackrel{\mathrm{x}}{=} \mathrm{s}(\mathrm{n})=(4.5) \mathrm{x} \log \mathrm{x}+0(\mathrm{x})
$$

where $s(n)$ denotes the digital sum of $n$. Here, we will show that, in fact, for any positive integer $k$,

$$
\mathrm{n} \sum_{0}^{\mathrm{x}} \mathrm{s}(\mathrm{kn})=(4.5) \mathrm{x} \log \mathrm{x}+0(\mathrm{x})
$$

where the constant implicit in the big-oh notation is dependent on $\mathrm{k}$.

The following notation will be used to facilitate the proof of (1.2). For integers $\mathbf{x}$ and $\mathrm{y}$,

$$
\mathrm{x} \bmod \mathrm{y}
$$

will be the remainder when $\mathrm{x}$ is divided by $\mathrm{y}$ and, as usual, square brackets will denote the integral part operator. In addition, for non-negative integers $\mathrm{m}, i$, and $j$ we let

$$
\begin{aligned}
& {[\mathrm{m}]^{j}=\mathrm{m} \bmod 10^{j},} \\
& {[\mathrm{~m}]_{i}=\left[\mathrm{m} / 10^{i}\right],}
\end{aligned}
$$


and

$$
[m]_{i}^{j}=\left[[m]^{j}\right]_{i}
$$

for $i<j$.

Thus, the $j$ right-most digits of $\mathrm{m}$ are given by (1.4) and the number determined by dropping the $i$ right-most digits of $\mathrm{m}$ is given by (1.5). Therefore, the number determined from the $j$ th right-most digit of $m$ to the $(i+1)$ st right-most digit of $m$ is given by (1.6).

2. A PROOF OF (1.2) WHEN $k$ AND 10 ARE RELATIVE PRIME.

Let $(k, 10)=1$, $x$ be a positive integer, and $L=[\log x]$. Then

$$
\begin{aligned}
& n \sum_{0}^{x} s(k n)=\sum_{n=0}^{x-1} s\left([k n]^{L}\right)+\sum_{n=0}^{x} s\left([k n]_{L}\right) \\
& =\sum_{n}^{\mathrm{x}} \mathrm{s}\left([\mathrm{kn}]^{\mathrm{L}}\right)+0(\mathrm{x}) .
\end{aligned}
$$

This follows since for non-negative integers $\mathrm{L}$ and $\mathrm{m}$,

$$
\mathrm{m}=[\mathrm{m}]^{\mathrm{L}}+10^{\mathrm{L}}[\mathrm{m}] \mathrm{L}
$$

and so

$$
s(m)=s\left([m]^{L}\right)+s\left([m]_{L}\right) .
$$

Also, since each $s\left([k n]_{L}\right)$ is bounded by a constant (dependent on $k$ ), we have that the second term of $(2.1)$ is $0(x)$.

Next, for $i=0,1,2, \ldots, L$ define

$$
x_{i}=[x]_{L+1-i} 10^{L+1-i}
$$

Then,

$$
\begin{aligned}
& \sum_{0}^{x} s\left([k n]^{L}\right)={ }_{n}^{x_{1}} \sum_{0}^{-1} s\left([k n]^{L}\right)+\sum_{n}^{x} s\left([k n]^{L}\right) \\
& =\sum_{n=0}^{x_{1}} s\left([k n]^{L}\right)+\sum_{n=x_{1}} s([k n] L-1)+\sum_{n=x_{1}}^{L} s\left([k n]^{L-1}\right) .
\end{aligned}
$$

In the same way,

$$
\begin{aligned}
\sum_{n=x_{1}}^{x} s\left([k n]^{L-1}\right) & ={ }^{x} \sum^{-1} s\left([k n]^{L-1}\right)+x_{1} \sum_{n=x_{2}}^{-1} s\left([k n]_{L-2}^{L-1}\right) \\
+ & \sum^{x} s\left([k n]^{L-2}\right) .
\end{aligned}
$$

Continuing in this manner and combining terms, we have

$$
\begin{aligned}
\sum^{x} \sum_{0}^{1} s\left([k n]^{L}\right) & =\sum_{i}^{L} x_{i} \sum^{-1} s\left([k n]^{L+1-i}\right) \\
+ & \sum_{i-1}^{L} x \sum^{L} s\left([k n]_{L-i}^{L+1-1}\right)
\end{aligned}
$$


Since

$$
s\left([k n]_{L-i}^{L+1-i}\right)
$$

is a decimal digit and

$$
x-x_{i}=[x]^{L+1-i} \leqq 10^{L+1-i}
$$

for each $i$, it follows that

$$
i \stackrel{L}{L} \sum_{=}^{x} x_{i} s\left([k n]_{L-i}^{L+1-i}\right)=0(x) .
$$

To determine the value of the first term of (2.8), we need the following lemma. Its proof is straight forward and will not be given.

LEMMA 2. Let $d$ and $i$ be non-negative integers. Then for $(k, 10)=1$,

$$
\left\{[k n]^{i}: n=d, d+1, \ldots, d+10^{i}-1\right\}=\left\{n: n=0,1, \ldots, 10^{i}-1\right\} .
$$

By this lemma and the fact that

$$
x_{i}-x_{i-1}=[x]_{L+1-i}^{L+2-i} 10^{L+1-i}
$$

it follows that

$$
{ }_{n}^{x_{i} \sum_{i-1}^{1} s\left([k n]^{L+1-i}\right)=\left([x]_{L+1-i}^{L+2-i}\right)} \sum_{n=0}^{10^{L+1-i}} s(n)
$$

for each $i$.

Now since

$$
\sum_{n=0}^{10^{L+1-i}-1} s(n)=4.5(L+1-i) 10^{L+1-i}
$$

by [2], we have that

$$
i=1 \quad n=x_{i-1}^{L} s\left([k n]^{L+1-i}\right)=(4.5) x \log x+0(x) .
$$

Using (2.16) and (2.11) in (2.8), by (2.2) we have the expression given in (1.2). The constant implicit in the big-oh notation is dependent on $k$ with $k$ and 10 relatively prime.

3. CONCLUSION.

For any positive integer $k$, there exists non-negative integers $a, b$, and $r$ such that $k=2^{a} 5^{b}$ with $(r, 10)=1$. Note that if $k=r$, then we have (1.2). However, by use of the following generalization to Lemma 2 , and some technical modifications, it can be shown that the restriction that $\mathrm{k}$ and 10 be relatively prime can be removed in the derivation of (2.1). That is,

$$
\mathrm{n} \sum_{0}^{\mathrm{x}} \mathrm{s}(\mathrm{kn})=(4.5) \mathrm{x} \log \mathrm{x}+0(\mathrm{x})
$$

for any positive integer $k$.

LEMMA 3. Let $k=2^{a} 5^{b}$ with $(r, 10)=1$ and $i \geqq \max \{a, b\}$. Then for any non- 
negative integer $d$,

$$
\begin{gathered}
\left\{[k n]^{i}: n=d, d+1, d+2, \ldots, d+\left(10^{i} / 2^{a} 5^{b}\right)-1\right\} \\
\quad=\left\{2^{a} 5^{b} n: n=0,1,2, \ldots,\left(10^{i} / 2^{a} 5^{b}\right)-1\right\} .
\end{gathered}
$$

Finally, based on the above techniques, it is strongly conjectured that for any positive integers $k_{1}$ and $k_{2}$, it again follows that

$$
\sum_{0}^{\mathrm{x}} \mathrm{s}\left(\mathrm{k}_{1} \mathrm{n}+\mathrm{k}_{2}\right)=(4.5) \mathrm{x} \log \mathrm{x}+0(\mathrm{x})
$$

\section{REFERENCES}

1. CHEO, P. and YIEN, S. A Problem on the K-adic Representation of Positive Integers, Acta Math. Sinica 5 (1955), 433-438.

2. KENNEDY, R.E. and COOPER, C.N. On the Natural Density of the Niven Numbers, College Math. Journal 15 (1984), 309-312. 


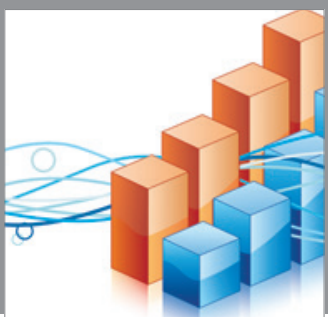

Advances in

Operations Research

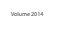

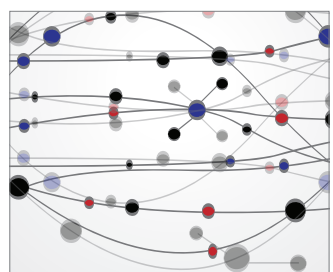

\section{The Scientific} World Journal
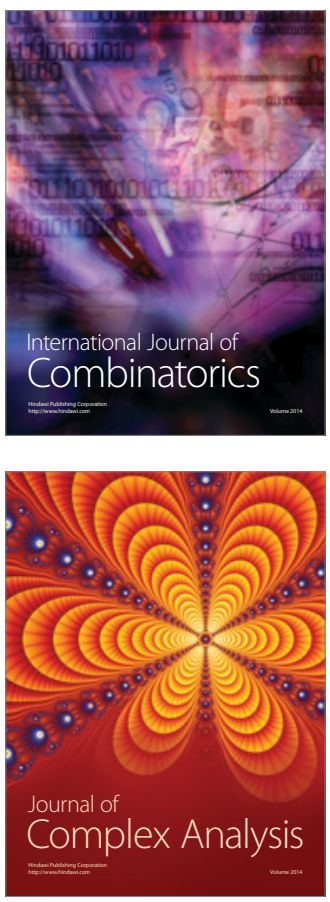

International Journal of

Mathematics and

Mathematical

Sciences
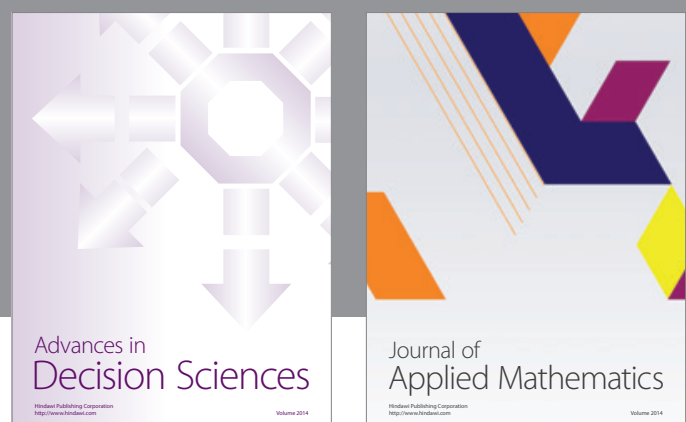

Journal of

Applied Mathematics
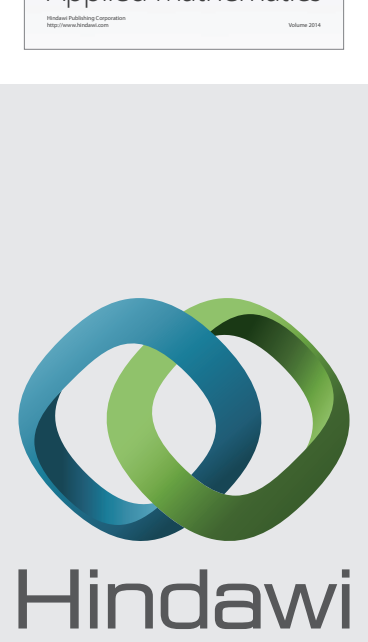

Submit your manuscripts at http://www.hindawi.com
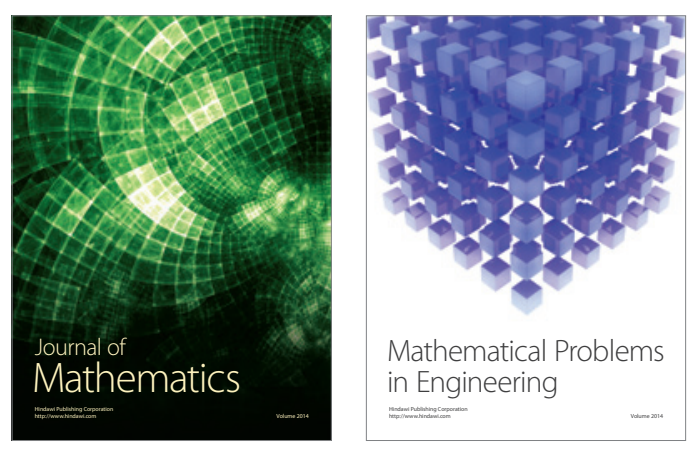

Mathematical Problems in Engineering
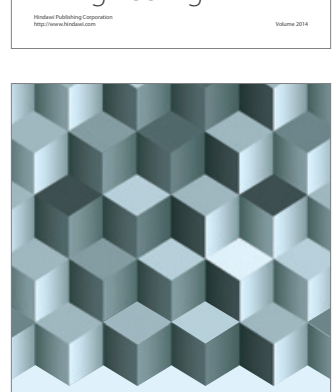

Journal of

Function Spaces
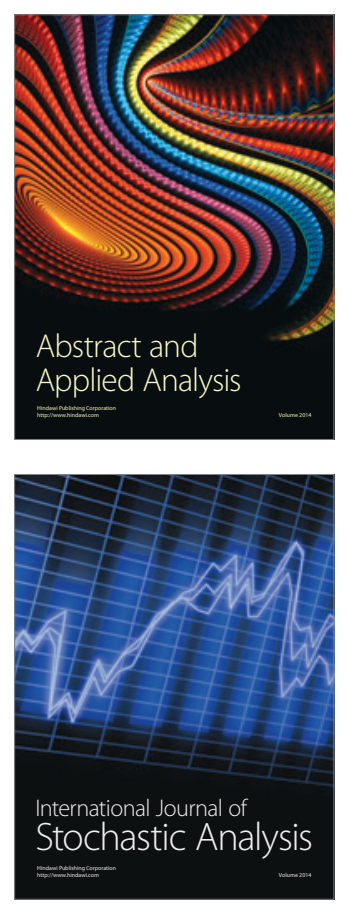

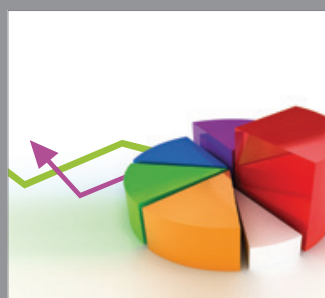

ournal of

Probability and Statistics

Promensencen
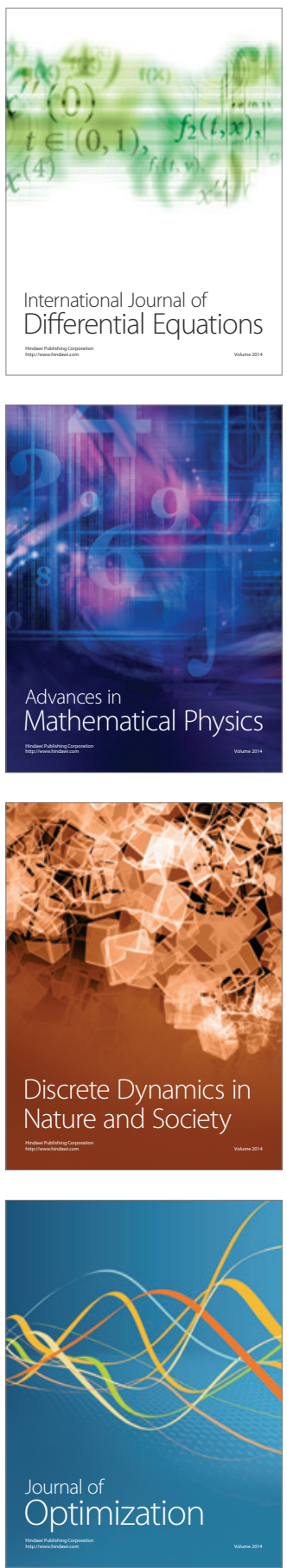